ORIGINAL ARTICLE

\title{
Patterns of Cardiac Arrhythmia in Haemodialysis Patients
}

\author{
*N Mahmood ${ }^{1}$, AMM Haq $^{2}$, ASM Giasuddin $^{3}$, KA Jhuma $^{4}$, MM Hoque $^{5}$, SS Chowdhury 6 \\ ${ }^{1}$ Dr. Nazneen Mahmood, Associate Professor, Department of Nephrology, AKMMC \\ ${ }^{2}$ Prof. Dr. AM Mujibul Haq, Honorary Professor of Medicine, Medical College for Women \& Hospital, Uttara, Dhaka \\ ${ }^{3}$ Prof.Dr. ASM Giasuddin, Head of Medical Research Unit, Medical College for Women \& Hospital, Uttara, Dhaka \\ ${ }^{4}$ Dr. Khadija Akther Jhuma, Associate Professor, Department of Biochemistry, Medical College for Women \& Hospital, Uttara, Dhaka \\ ${ }^{5}$ Dr. Md Mahbubul Hoque, Assistant Professor of Medicine. Medical College for Women \& Hospital, Uttara, Dhaka \\ ${ }^{6}$ Dr. Shaila Safia Chowdhury, Assistant Professor of Medicine, Medical College for Women \& Hospital, Uttara, Dhaka
}

*Corresponding Author

Date of submission: 15 October 2015 Date of acceptance: 02 December 2015

\begin{abstract}
Background: Cardiovascular disorders are one of the most serious problems in chronic haemodialysis patients. According to the records of last 15 years, $50 \%$ of these patients died from cardiovascular complications every year, without a marked reduction in the annual frequency of deaths. Cardiac arrhythmias are frequently associated with haemodialysis and have been reported to be seen in some series in up to $76 \%$ of patients.
\end{abstract}

Materials \& Methods: They appear to occur mostly after the first 3 hours of dialysis. In this study we have evaluated the arrhythmias that occured before and during dialysis to reduce the burden of morbidity and mortality of the patients. This is a cross sectional descriptive type of observational study on haemodialysis patients in Medical College for Women and Hospital (MCWH). Duration of study was 2 years, from July 2011 to June 2013.All the patients of end stage renal disease (ESRD) on maintenance haemodialysis (MHD) were included in the study. 81 patients were included to the study. One patient had permanent pacemaker and was excluded. Four patients had died during the study and four patients did not co-operated and left the study. Holter monitoring of a patient was unreadable because of artifact. Finally 71 patients were studied.

Results: Out of 71 patients 38 were males and 33 were females with male to female ratio of 1.5:1. The mean age of the patient was 50.8112 .45 ( Range-22-75 ) year. Among 71 patients 19 had both DM and HTN and 42 patients had only HTN and 10 patients had other causes of chronic kidney disease (CKD).Premature atrial contraction(PAC) $27(40.30 \%)$ and Premature ventricular contraction(PVC) 40(59.70\%)were the most common arrhythmia in dialysis patients before and during dialysis in our study. We found no significant effect of heamodialysis (HD) on cardiac arrhythmia. There was no correlation between arrhythmia and changes in $\mathrm{Hb} \%, \mathrm{HbA1C}, \mathrm{S}$. Albumin, S Creatinine, ions changes $(\mathrm{Na}+, \mathrm{K}+, \mathrm{Ca}++, \mathrm{Mg}++)$ before and during haemodialysis (HD). QT intervals had no significant increase in dialysis patients. The prevalence of Atrial fibrillation (AF) rhythm was 5.63\%.A high prevalence of cardiovascular disease is observed in end stage renal disease(ESRD) patients receiving dialysis therapy.

Conclusion: The number of arrhythmias did not increase during dialysis in patients with no history of cardiac diseases, so the dialysis itself is not a leading risk factor for arrhythmias. But if a patient has history of arrhythmia, ischemia or left ventricular hypertrophy $(\mathrm{LVH})$, he should be monitored during haemodialysis or undergo peritoneal dialysis in order to reduce the arrhythmia risk.

Key Wards: CardiacArrhythmia, Haemodialysis, End stage renal disease

\section{Introduction}

Cardiovascular disorders are one of the most serious problems in chronic haemodialysis patients. According to the records of last 15 years, $50 \%$ of these patients died from cardiovascular complications every year, without a marked reduction in the annual frequency of deaths ${ }^{1}$. This gains even more importance when we consider the fact that, according AKMMC J 2016; 7(1) : 28-33 to Annual Report of USA Renal Data 1997, during the first year of treatment substitution a total reduction in the death rate from 30 to $24 \%$ has been achieved $^{1}$. This reduction is due to better follow-up and management of patients before their integration in programs of chronic renal dialysis. 
The mortality due to cardiovascular disease in haemodialysis patients is estimated to be $9 \%$ annually and is 30 times higher than that observed in the general population. Even after correction for age, this percentage remains 10-20 fold higher than in the general population ${ }^{2}$. Cardiac arrhythmias are frequently associated with haemodialysis and have been reported to be seen in some series in up to $76 \%$ of patients ${ }^{3}$. They appear to occur mostly after the first 3 hours of dialysis ${ }^{3}$.

The worldwide dialysis population is estimated to be greater than 1.1 million persons ${ }^{4}$. Compared to Japan, Taiwan and United States most countries have a lower incidence of treated end stage renal disease( ESRD) ${ }^{4}$. Hemodialysis is the predominant technique for treating ESRD throughout the world. In the United States, $87 \%$ of the patients start their ESRD care with hemodialysis ${ }^{5}$. Approximately $100-120$ patients per million population (pmp) reaches ESRD every year in Bangladesh, which is not very different what is being reported from countries in Asia and Middle East ${ }^{6}$.

Dialysis patients have extra ordinary high mortality rates. The annual mortality rate for prevalent United States dialysis patients in 2004 was 230 deaths per 1000 patients-year 7,8 . Cardiac disease is the major cause of death, accounting for $43 \%$ of all cause of mortality among patients receiving haemodialysis or peritoneal dialysis ${ }^{7,8}$. In the United States Renal Data System (USRDS) database, the single largest cause of death is attributed to arrhythmic mechanisms: $58 \%$ of all cardiac death (or $25 \%$ of all-cause mortality) among peritoneal dialysis patients and $64 \%$ of all cardiac death (or $27 \%$ of all-cause mortality) among haemodialysis patients are due to "cardiac arrest/cause unknown" or arrhythmia ${ }^{7,8}$.

Cardiovascular diseases(CVD) are responsible for more than $40 \%$ of death in dialysis patients (DP) and the burden of their morbidity is high ${ }^{9,10}$. Some studies showed that CVD mortality is about $9 \%$ per year in dialysis patients which is 30 times more than community mortality. Some patients death suddenly which indicate deaths due to serious arrhythmia ${ }^{11}$. It is documented that if QT interval (the QT interval is a measure of the time between the start of $\mathrm{Q}$ wave and the end of $T$ wave in the heart's electrical cycle) be pathologically more than the normal range in healthy individual leads to dangerous arrhythmia and increase mortality rate ${ }^{12}$. Many factors such as cardiac electrical disturbance, antiarrhythmia drugs, phenothiazines, tricyclic and quadric cyclic antidepression drugs, lithium and antibiotics (Ampicillin, Erythromycin) can lead to QT interval increase $^{13,14}$. Kidney dysfunction in dialysis patients lead to an ion level abnormalities and the $\mathrm{Ca}^{2}+$, $\mathrm{K}+$ and $\mathrm{Mg}^{2}+$ ion balance will be disturbed. This imbalance affects heart cell's resting membrane potential and therefore causes changes in QT interval. Increased QT interval can cause most arrhythmias in dialysis patients and lead to death ${ }^{15}$. Most clinicians avoid dialysing poor prognosis patients because of new arrhythmias occurrence probability during dialysis and sudden death. Although arrhythmias occurring during dialysis do not appear to increase mortality, they are associated with increase morbidity ${ }^{16}$. In this study we will evaluate the arrhythmias that will occur before and during dialysis to reduce the burden of morbidity and mortality of the patients.

\section{Materials and Methods}

This is a cross sectional descriptive type of observational study on haemodialysis patients in Medical College for Women and Hospital. Duration of study was 2 years, from July 2011 to June 2013. All the patients of end stage renal disease (ESRD) onmaintenance haemodialysis (MHD) were included in the study. ESRD was defined as e GFR $<5 \mathrm{ml} / \mathrm{min} / 1.73 \mathrm{~m} 2$ body surface area according to recommendation of K-DOQI guideline 17. There were no exclusion criteria related to the duration of dialysis, the first time of dialysis and the main cause of dialysis. Patients with known diseases such as myocardial infarction, cardiomyopathy and valvular heart disease were excluded from the study. Also the patients consuming anti-arrhythmic drugs, phenothiazine, anti- depressant drugs and antibiotics (which might affect QT interval) were excluded. Written consent were taken from the patients. All clinical and biochemical parameters of the patients were noted on data collection sheet.

All the cases were connected with the cardiac monitor just before dialysis and during dialysis. 12 lead electrocardiographs were done and QT interval was measured in lead 11 by the cardiologist before dialysis. QT interval was adjusted according to Bazett's formula $(\mathrm{QTc}=\mathrm{QT} / \mathrm{RR})$. M mode, two dimentional echocardiography (ALT-6) was done for 
all patients to asses pericardial effusion and ejection fraction. Holter monitoring (Holter BMS) has been done 24 hours before dialysis and during dialysis. The holter monitoring results were assessed by the cardiologist and they have recorded the arrhythmias and their frequencies before and during dialysis.

Blood samples were drawn in the morning, all the subjects was rested for at least 10 minutes before blood sampling. Venous blood was collected from the anticubital vein of the hand of the patients without AV fistula with minimal stasis without frothing using standard equipment. Serum was separated and refrigerated $(4 \mathrm{oC})$, aliquoted and preserved at $-80 \mathrm{o} C$ until analysed by the immunoassay (EIA) system using research kits. Biochemical tests- serum creatinine, serum electrolytes $\left(\mathrm{Na}^{+}, \mathrm{K}^{+}, \mathrm{Ca}^{2+}\right.$, $\mathrm{Mg}^{2+}, \mathrm{PO}^{2-}$ ), blood urea nitrogen, lipid profile, HbA1C, random blood sugar, haemoglobin, serum albumin, e GFR have been done before and during dialysis in the department of biochemistry of Medical College for Women \& Hospital (MCWH). All the data were processed and analyzed using computer software SPSS(Statistical Package for Social Science) version 16 according to Data Processing Plan. The test statistics used to analyze the data were descriptive statistics, Paired Student's t-test. Results were expressed as Mean Standard Deviationfor continuous data and as frequency with percentages for categorical data. Categorical data were expressed as percentages and evaluated using Paired Student's t-test. The level of significance was 0.05 . P-value < 0.05 was considered significant. The summarized information was then expressed in the form of tables and charts.

\section{Results}

81 patients were included to the study. One patient had permanent pacemaker and was excluded. Four patients had died during the study and four patients did not co-operated and left the study. Holter monitoring of a patient was unreadable because of artifact. Finally 71 patients were studied. Out of 71 patients 38 were males and 33 were females with male to female ratio of $1.5: 1$. The mean age of the patient was 50.8112 .45 ( Range-22-75 )year.

The main characteristics of samples were shown in Table-1. The main cause of end stage renal disease were hypertension (HTN) and diabetes mellitus
(DM). Among 71 patients 19 had both DM and HTN and 42 patients had only HTN and 10 patients had other causes of chronic kidney disease (CKD).

Premature atrial contraction(PAC) $27(40.30 \%)$ and Premature ventricular contraction(PVC) 40(59.70\%) were the most common arrhythmia in dialysis patients before and during dialysis in our study (Table-2). We also noted that, there was no significant difference in PAC \& PVC before and during haemodialysis (HD). We found no significant effect of HD on cardiac arrhythmia (Table-3). Their prevalence did not have significant relationship with ion changes $\left(\mathrm{Na}^{+}, \mathrm{K}^{+}, \mathrm{Ca}^{++}, \mathrm{Mg}^{++}\right)$the dialysis quality, severity of anemia and the duration of dialysis. There was no correlation between arrhythmia and changes in $\mathrm{Hb} \%, \mathrm{HbA}_{1} \mathrm{C}, \quad \mathrm{S}$. Albumin, $\mathrm{S}$ Creatinine, ions changes before and during HD (Table-4). QT intervals had no significant increase in dialysis patients. The prevalence of Atrial fibrillation (AF) rhythm was $5.63 \%$ (Table-1).

Table-I: The main characteristics of the study group.

\begin{tabular}{ll}
\hline Varables & N-71 \\
\hline Age( Mean- SD) & $50.81-12.45$ \\
Age Range & $22-75$ \\
Etiology of Renal diseases(\%) & \\
DM & $19(26.76 \%)$ \\
HTN & $42(59.16 \%)$ \\
Others & $10(14.08 \%)$ \\
Duration of Haemodialysis & $1-24$ months \\
EF(\%) & \\
Abnormal( less than 60\%) & $12(16.90 \%)$ \\
Normal & $59(83.10 \%)$ \\
LVH(\%) & $41(57.75 \%)$ \\
AF(\%) & $4(5.63 \%)$ \\
Pericardial effusion(\%) & $26(36.62 \%)$ \\
\hline
\end{tabular}

Table-II: Distribution of patients according to Patterns of Arrhythmia

\begin{tabular}{lll}
\hline Patterns of Arrhythmia & No & \% \\
\hline $\begin{array}{l}\text { Premature Atrial } \\
\text { Contraction (PAC) }\end{array}$ & 27 & 40.30 \\
$\begin{array}{l}\text { Premature Ventricular } \\
\begin{array}{l}\text { Contraction (PVC) } \\
\text { Total }\end{array}\end{array}$ & 40 & 59.70 \\
\hline
\end{tabular}


Table-III: Frequency of Arrhythmia Before and During Haemodialysis

\begin{tabular}{|c|c|c|c|}
\hline Arrhythmia & $\begin{array}{l}\text { Before } \\
\text { Haemodialysis } \\
(M \pm S D)\end{array}$ & $\begin{array}{l}\text { During } \\
\text { Haemodialysis } \\
(\mathrm{M} \pm \mathrm{SD})\end{array}$ & P-value \\
\hline $\begin{array}{l}\text { Premature Ventricular } \\
\text { Contraction(PVC) }\end{array}$ & 58.217 .3 & 64.425 .4 & -1.27 \\
\hline $\begin{array}{l}\text { Premature Atrial } \\
\text { Contraction(PAC) }\end{array}$ & 60.514 .6 & 63.412 .5 & -0.785 \\
\hline
\end{tabular}

Table-IV: The effects of multiple factors on PVC \& PAC before \& during haemodialysis

\begin{tabular}{|c|c|c|c|c|}
\hline Variables & $\begin{array}{c}\text { Before } \\
\text { Haemodialysis } \\
(\mathrm{M} \pm \mathrm{SD})\end{array}$ & $\begin{array}{c}\text { During } \\
\text { Haemodialys } \\
\text { is } \\
(\mathrm{M} \pm \mathrm{SD})\end{array}$ & $\begin{array}{l}\text { PVC } \\
(n=40)\end{array}$ & $\begin{array}{l}\text { Student's } t \text { test } \\
\text { PAC } \\
(\mathrm{n}=27)\end{array}$ \\
\hline $\mathrm{Hb} \%(\mathrm{gm} / \mathrm{dl})$ & $9.7 \pm 1.25$ & $9.5 \pm 1.45$ & $\begin{array}{l}t=0.664 d f=78 \\
P>0.05\end{array}$ & $\begin{array}{l}\mathrm{t}=0.544 \mathrm{df}=52 \\
\mathrm{P}>0.05\end{array}$ \\
\hline $\mathrm{HbA}_{1} \mathrm{C}(\%)$ & $6.81 \pm 1.45$ & $6.67 \pm 1.12$ & $\begin{array}{l}t=0.486 \mathrm{df}=78 \\
P>0.05\end{array}$ & $\begin{array}{l}t=0.397 \mathrm{df}=52 \\
\mathrm{P}>0.05\end{array}$ \\
\hline S. Albumin(gm) & $38.79 \pm 3.33$ & $37.71 \pm 3.24$ & $\begin{array}{l}\mathrm{t}=1.44 \mathrm{df}=78 \\
\mathrm{P}>0.05\end{array}$ & $\begin{array}{l}t=1.19 d f=52 \\
P>0.05\end{array}$ \\
\hline $\begin{array}{l}\text { S.Creatinine } \\
(\mathrm{mg} / \mathrm{dl})\end{array}$ & $5.9 \pm 1.9$ & $5.5 \pm 1.4$ & $\begin{array}{l}t=1.075 d f=78 \\
P>0.05\end{array}$ & $\begin{array}{l}t=0.873 \mathrm{df}=52 \\
\mathrm{P}>0.05\end{array}$ \\
\hline S. $\mathrm{Na}^{+}(\mathrm{mmol} / \mathrm{L})$ & $135.8 \pm 5.9$ & $134.7 \pm 5.3$ & $\begin{array}{l}t=0.898 d f=78 \\
P>0.05\end{array}$ & $\begin{array}{l}\mathrm{t}=0.722 \mathrm{df}=52 \\
\mathrm{P}>0.05\end{array}$ \\
\hline $\mathrm{S} \cdot \mathrm{K}^{\cdot}(\mathrm{mmol} / \mathrm{L})$ & $5.3 \pm 1.0$ & $5.2 \pm 1.0$ & $\begin{array}{l}t=0.896 \mathrm{df}=78 \\
P>0.05\end{array}$ & $\begin{array}{l}t=0.735 d f=52 \\
P>0.05\end{array}$ \\
\hline S.Ca ${ }^{++}(\mathrm{mg} / \mathrm{dl})$ & $8.7 \pm 1.2$ & $8.3 \pm 1.4$ & $\begin{array}{l}t=0.434 d f=78 \\
P>0.05\end{array}$ & $\begin{array}{l}t=1.13 \mathrm{df}=52 \\
P>0.05\end{array}$ \\
\hline $\mathrm{S} . \mathrm{Mg}^{++}(\mathrm{mmol} / \mathrm{L})$ & ) $3.4 \pm 0.9$ & $3.2 \pm 0.7$ & $\begin{array}{l}t=1.12 \mathrm{df}=78 \\
P>0.05\end{array}$ & $\begin{array}{l}t=0.913 \mathrm{df}=52 \\
\mathrm{P}>0.05\end{array}$ \\
\hline
\end{tabular}

Premature Ventricular Contraction (PVC), Premature Atrial Contraction (PAC)

\section{Discussion}

The mean age of the patients was 50.8112 .45 year which is similar to other studies. In a study of Hamidreza Nasri et al mean age was 47.916 .1 year ${ }^{9}$. In other studies the mean age of patients had been reported from 38.2 year in 1997 to 52.5 in $2007^{10,18,19}$. It seems better control and management of disease leading to dialysis leads to later presentation of renal complications. Probably in next decade we will have the same change in our country as chronic diseases such as hypertension and diabetes are controlling better.

The most common cause of end stage renal disease was hypertension in our study which was similar to study by Hamidreza Nasri et $\mathrm{al}^{9}$. The statistics show that diabetes is the most common cause in developing countries ${ }^{12}$.

Paroxysmal atrial fibrillation attack is one of the most common tachyarrhythmia in maintenance haemodialysis (MHD) patients. Paroxysmal atrial fibrillation attack not only can affect the dialysis to proceed smoothly, but also it can increase the death risk in MHD patients. The prevalence of atrial fibrillation (AF) arrhythmia was $5.63 \%$ in our study. In the study of Hamidreza Nasri et al it was $2.7 \%^{9}$. In another study of Benjamin EJ et al AF has been reported approximately $12 \%^{20}$. May be the lower AF was due to lower mean age of our patients. Increasing age will increase the prevalence of $\mathrm{AF}$ even in non dialysis individuals ${ }^{21}$. The dialysis has no effect of incidence of new AF.

In a study of Korantzopoulos $\mathrm{P}$ et al the incidence of $\mathrm{AF}$ in patients with end stage renal disease (ESRD) is between 1 and 4.1 per 100 patient-years ${ }^{22}$. Vazquez et al extended previous observations to report on the prevalence and incidence of AF in a cohort of patients who started dialysis at that group's center and who were followed for a mean period of 2 years. The AF prevalence was noted as $12.1 \%$, and the incidence, as 5.9 per 100 patientyears $^{23}$.

Premature atrial contraction (PAC) $27(40.30 \%)$ and Premature ventricular contraction (PVC) $40(59.70 \%)$ were the most common arrhythmia in dialysis patients before and during dialysis in our study. We also noted that, there was no significant difference in PAC \& PVC before and during haemodialysis (HD). We found no significant effect of HD on cardiac arrhythmia. Their prevalence did not have significant relationship with ion changes $\left(\mathrm{Na}^{+}, \mathrm{K}^{+}, \mathrm{Ca}^{++}, \mathrm{Mg}^{++}\right)$the dialysis quality, severity of anemia and the duration of dialysis. There was no corelation between arrhythmia and changes in $\mathrm{Hb} \%$, $\mathrm{HbA}_{1} \mathrm{C}$, S. Albumin, S Creatinine, ions before and during HD. In a study of Hamidreza Nasri PAC was $40 \%$ and PVC was $64 \%$ before and during HD and they also found no sigficant difference between arrythmia before and during $\mathrm{HD}$, none with the other factors, which was similar to our study?

The dialysis duration was lower (1-24 months) in this study, whereas 1-180 months in the study of Hamidreza Nasri and 9-218 months in developing countries $^{9,18}$. It's may be due to higher annual mortality rate of our patients. 
QTc did not increase in our study $(\mathrm{QTc}=0.38$ $0.02 \mathrm{~s}$ ), which was similar to study of Hamidreza Nasri which was $0.40-0.04 s^{9}$. In a study in Europe QTe was 0.43-0.02s and the patients who had more arrhythmia had higher $\mathrm{QT}^{15}$. Shorter dialysis duration and lower electrolytes disturbances may affect QT in our patients. Long dialysis, even if performing perfectly can cause ions imbalance and lead to QT changes. $\mathrm{Ca}^{2+}, \mathrm{K}^{+}, \mathrm{Mg}^{2+}$ ions role in QT interval is so various and complex, so the QT variation are not easily explained. Hyperkalaemia leads to shorter QT interval in primary stage. Hypocalcaemia can increase QT interval and hypermagnesemia can increase QT and arrhythmia.

Some studies reported Hematocrit(Hct) 22.8-5, but it was 32.6-5.5 in our study ${ }^{18}$. Hamidreza Nasri showed Hct 30.7-6.5 in their study ${ }^{9}$. It showed that anaemia severity was lower in our patients. The lower anaemia rate was due to shorter dialysis period. Anaemia can worse the myocardial ischemia and leads to arrhythmia ${ }^{18}$.

A study carried out in Poland showed that the prevalence of cardiac arrhythmias in peritoneal dialysis is lower and premature ventricular contraction (PVC) has been detected in $30-43.3 \%$ of patients and supra ventricular arrhythmia were seen in $40-56.7 \%^{24}$. They conclude that peritoneal dialysis does not provoke or aggravate arrhythmia.

Silent myocardial ischemia(MI) and ventricular arrhythmia in patients during dialysis has been well recognized. In a study Holter monitoring showed silent MI in $22 \%$ cases during dialysis ${ }^{19}$. A significant increase happened in the frequency of ventricular arrhythmias during and after dialysis. It claims that silent myocardial ischemia is an arrhythmogenic process and predisposes a clinically significant ventricular arrhythmia during and after dialysis ${ }^{19}$.

We found no statistically significant differences between patients with or without ventricular arrhythmia in urea, calcium, potassium and magnesium blood concentrations but there was a statistically significant difference between groups of creatinine values. Another study indicated that ventricular arrhythmia appears in the majority of haemodialysis patients and that haemodialysis intencifies arrhythmogenic influence of irreversible renal failure on heart. It is also possible that nonadequate haemodialysis (HD) might be responsible for ventricular arrhythmias during and after dialysis ${ }^{25}$.

HD is potentially arrhythmogenic procedure in patients with preexisting cardiac disease ${ }^{26}$. May be the lower incidence rate of arrhythmia is due to exclusion of patients with cardiac disease history. There was only one study which confirmed our results and showed that chronic haemodialysis did not enhance the risk of malignant arrhythmias in patients with end stage renal disease (ESRD).

\section{Conclusion}

A high prevalence of cardiovascular disease is observed in end stage renal disease(ESRD) patients receiving dialysis therapy. Most of these cardiovascular complications are already established and advanced by the time patients are started on dialysis treatment, thus indicating the need for earlier and more active screening for cardiovascular disease.

Our limitation of the study was Holter monitoring device deficiency. If we had more Holters we could compare the QT interval and arrhythmias (PAC and PVC) of the patients with a control group, so our result were more precious. The number of arrhythmias did not increase during dialysis in patients with no history of cardiac diseases, so the dialysis itself is not a leading risk factor for arrhythmias.

But if a patient has history of arrhythmia, ischemia or left ventricular hypertrophy(LVH), he should be monitored during haemodialysis or undergo peritoneal dialysis in order to reduce the arrhythmia risk.

\section{Acknowledgement}

We would like to thank all the patients, personnel of haemodialysis department of Medical College for Women and Hospital, Uttara, Dhaka for their kind cooperation. I would like to thank Prof. Md. Roushan Ali, Head of the Department of Medicine \& Cardiology for his kind help regarding cardiac evaluation of the patients.

Conflict of interest : We have no conflict of interest. 


\section{References}

1. United States Renal Data System: The USRDS Dialysis Morbidity and Mortality Study: Wave 2. Am J Kidney Dis 1997;30:S67-S85.

2. Coronado BE, Bu D, Levey AS, Meyer KB: Controlling the Epidemic of Cardiovascular disease in chronic renal disease: What do we know? What do we need to learn? Where do we go from here? The Process and Bibliography. Am J Kidney Dis 1998;32:14-55.

3. Gruppo Emodialisisi e Patologie Cardiovascolari: Multicentre, cross-sectional study of ventricular arrhythmias in chronically haemodialysed patients. J Am Soc Nephrol1995; 6:564(abstr).

4. Goodman WG \& Danovitch GM. Options for patients with kidney failure. In: Handbook of Kidney Transplantation. Philadelphia: Lippincott William \& Wilkins 4th edition. 2008; 3-21.

5. US Renal Data System. Excerpts from the USRDS 2003 annual data report: atlas of end stage renal disease in the United States. Am J Kidney Dis. 2003; 42 (Suppl 5): 4-224.

6. Rashid HU. Bangladesh renal registry report (19861996) Bangladesh renal J 2002; 21(1):25-28.

7. US Renal Data System: USRDS 2006 Annual Data Report. Bethesda MD: National Institute of Health, National Institute of Diabetes and Digestive and Kidney disease, 2006.

8. Charles A, Herzog J, Michael Mangrum, Rod Passman. Sudden Cardiac Death and Dialysis Patients. Seminars in Dialysis.2008; Vol 21 No 4(July- August):300-307.

9. Hamidreza Nasri, Behzad Sarver Azimzedeh, Mohamadhosein Torabinejad, Reza Pourakbari.Cardiac Arrhythmia in Dialysis Patients. ARYA Atherosclerosis Journal 2008,3(4):223-226.

10. Parfrey PS. Cardiac and cerebrovascular disease in chronic uremia.Am J Kidney Dis.1993; 21(1):77 80.

11. Foley RN, Palfrey PS, Sarnak MJ. Clinical epidemiology of cardiovascular disease in chronic renal disease. Am J Kidney Dis. 1993; 32(suppl 3):184-99.

12. Lindner A Charra B, Sherrard DJ, Scribner BH: Accelerated atherosclerosis in prolong maintenance hemodialysis. N Engl J Med 1974; 290: 697-701.

13. Frost L, Engholm G, Moeller R, Husted S. Decrease in mortality in patients with a hospital diagnosis of atrial fibrillation in Denmark during the period 19801993.Europian heart journal 1999;20:1592-9.

14. Ewing DJ, Boland O, Neilson JM, Clark BF. Autonomic neuropathy, QT interval lengthening and unexpected death in male diabetic patients. Dialectologist 1991; 34: 182-185.
15. Kahn JK, Sisson JC, Vinik AI. QT interval prolongation and sudden cardiac death in diabetic autonomic neuropathy. J Clin Endocrinol Metab 1987;64:751-754.

16. Sforzini S, Latini R, Mingerdi G, Vincenti A, Redaelli B: Ventricular arrhythmias and four year mortality in haemodialysis patients. Lancet 1992; 339: 212-213.

17. NKF-DOQI. Clinical Practice Guideline for Chronic Kidney Disease: Evaluation, Classification and Stratification. Executive summery. New York, 2002; 10,22,23. www. K.doqi.org.

18. Salgueira M, Milan JA, Moreno Alba R, Amor J, Areste N, Jimenez E et al. Cardiac failure and diastolic dysfunction in haemodialysis patients: associated factors. Nephrologia. 2005; 25(6): 668-677.

19. Mohi-ud-din, Bali HK, Banerjee S, Sakhuja V, Jha V. Silent myocardial ischemia and high- grade ventricular arrhythmias in patients on maintenance haemodialysis. Ren Fail. 2005; 27(2): 171-5.

20. Benjamin EJ, Wolf PA, D'Agostino RB et al. Impact of atrial fibrillation on the risk of death: the Framingham Heart Study. Circulation 1998; 98: 946-52.

21. Jeffery E. Olgin. Douglas P. Zipes. Specific Arrhythmias: Diagnosis and Treatment. Chapter 32. In Braunwald heart disease 7th Edition Elsevier Saunders 2005.

22. Korantzopoulos P, Kokkoris S, Liu T, Protopsaltis I, Li G, Gourdevenos JA. Atrial fibrillation in end-stage renal disease. Pacing Clin Electrophysiol 2007; 30: 1391-7.

23. Vazquez E, Sanchez-Perales C, Borrego F, et al. Influence of atrial fibrillation in morbidity-mortality of patients on haemodialysis. Am Heart J 2000; 140: 88690.

24. Renke M, Zegrzda D, Liberec T, Dudziak M, Lichodziejews-ka-Niemierko M, Kubasik A, Rutkowski B. Interrelationship between cardiac structure and function and incidence of arrhythmia in peritoneal dialysis patients. Int J Artif Organs. 2001; 24(6): 374-9.

25. Switalski M, Kepka A, Galewicz M, Figatowski W, Malinski A. Ventricular arrhythmia in patients with chronic renal failure treated with haemodialysis. Pol Arch Med Wewn. 2000; 104(4): 703-8.

26. Kyriakidis M, Voudiclaris S, Kremastinos D, RobinsonKyriakidis C, Vyssoulis G, Zervakis D, Toutouzas P, Komninos Z, Avgoustakis D. Cardiac arrhythmia in chronic renal failure. Holter monitoring during dialysis and everyday activity at home. Nephron. 1984; 38(1): 26-9. 